\title{
¿DE QUÉ MUEREN LAS MADRES CHILENAS EN EL SIGLO XXI? CAMBIO DEL PERFIL EPIDEMIOLÓGICO
}

En abril de 2009, el Instituto Nacional de Estadísticas entregó el anuario de Estadísticas Vitales correspondiente al año 2006 (1). Se notificaron 47 muertes derivadas de complicaciones del embarazo, parto y puerperio (códigos O00-99, CIE 10) y 243.561 nacidos vivos (nv) corregidos, que determina una tasa de mortalidad materna de 19,3/100.000 nv. Las causas de los fallecimientos, se presenta en la Tabla I.

Del análisis observacional de esa Tabla destaca que las muertes maternas por enfermedades concurrentes (código O99), con 17 fallecimientos, continua siendo la primera causa de muerte materna en Chile. Este grupo de causas entre 2000-2003 mantenía un promedio de 7 muertes anuales y en 2004 subieron al doble con 15 fallecimientos y 17 en $2005(2,3)$, hecho que fue atribuido al aumento de la natalidad en mujeres en edad reproductiva avanzada $(4,5)$. En 2006, de las 17 madres fallecidas, $4(23,5 \%)$ tenían una edad entre 40-44 años, lo que nuevamente certifica el alto riesgo de ese rango etario $(4,5,6)$. Las patologías consideradas en el código O99 de CIE 10 se presentan en la Tabla II.

El perfil epidemiológico de las muertes maternas en Chile en el siglo XXI ha cambiado. La mortalidad materna por aborto séptico ya no es un problema de salud pública (7), como continua siendo en la mayoría de los países en desarrollo de la Región de las Américas. El envejecimiento poblacional de las mujeres en edad fértil, sumado a la postergación de la maternidad, hace que los nacimientos en mujeres de 40 o más años aumenten (8), y explican que las enfermedades concurrentes sean en la actualidad la primera causa de muerte materna en Chile. Las estrategias para el control de la mortalidad en esas mujeres son el adecuado consejo reproductivo pregestacional, una adecuada planificación familiar y control de sus embarazos en el nivel terciario.
Tabla I

CAUSAS DE MUERTE MATERNA, CHILE 2006

\begin{tabular}{|c|c|c|}
\hline CÓDIGO & CAUSA & $\mathrm{n}$ \\
\hline $\mathrm{O} 00$ & Embarazo ectópico & 4 \\
\hline 006 & Aborto no especificado & 3 \\
\hline 013 & $\begin{array}{l}\text { Hipertensión gestacional, } \\
\text { sin proteinuria significativa }\end{array}$ & 1 \\
\hline 014 & $\begin{array}{l}\text { Hipertensión gestacional, } \\
\text { con proteinuria significativa }\end{array}$ & 6 \\
\hline O15 & Eclampsia & 3 \\
\hline O16 & $\begin{array}{l}\text { Hipertensión materna } \\
\text { no especificada }\end{array}$ & 2 \\
\hline $\mathrm{O} 22$ & $\begin{array}{l}\text { Complicaciones venosas } \\
\text { en el embarazo }\end{array}$ & 1 \\
\hline $\mathrm{O} 24$ & $\begin{array}{l}\text { Diabetes mellitus en el } \\
\text { embarazo }\end{array}$ & 1 \\
\hline $\mathrm{O} 62$ & $\begin{array}{l}\text { Anormalidades de la } \\
\text { dinámica del trabajo } \\
\text { de parto }\end{array}$ & 1 \\
\hline $\mathrm{O} 72$ & Hemorragia posparto & 2 \\
\hline $\mathrm{O} 75$ & $\begin{array}{l}\text { Otras complicaciones } \\
\text { del trabajo de parto y } \\
\text { del parto, no clasificadas } \\
\text { en otra parte }\end{array}$ & 1 \\
\hline O87 & $\begin{array}{l}\text { Complicaciones venosas } \\
\text { en el puerperio }\end{array}$ & 1 \\
\hline $\mathrm{O} 88$ & Embolia obstétrica & 3 \\
\hline O98 & $\begin{array}{l}\text { Enfermedades maternas } \\
\text { infecciosas y parasitarias } \\
\text { clasificables en otra parte, } \\
\text { pero que complican el e } \\
\text { mbarazo, el parto y el } \\
\text { puerperio pero que } \\
\text { complican el embarazo, } \\
\text { el parto y el puerperio }\end{array}$ & 1 \\
\hline O99 & $\begin{array}{l}\text { Otras enfermedades } \\
\text { maternas clasificables } \\
\text { en otra parte }\end{array}$ & 17 \\
\hline O00-99 & Todas las causas & 47 \\
\hline
\end{tabular}


Tabla II

CÓDIGO O99: OTRAS ENFERMEDADES MATERNAS CLASIFICABLES EN OTRA PARTE, PERO QUE COMPLICAN EL EMBARAZO, EL PARTO Y EL PUERPERIO (CIE-10)

\section{CÓDIGO PATOLOGÍAS}

O99.0 Anemia que complica el embarazo, el parto y el puerperio.

O99.1 Otras enfermedades de la sangre y de los órganos hematopoyéticos y ciertos trastornos que afectan el sistema inmunitario cuando complican el embarazo, el parto y el puerperio.

O99.2 Enfermedades endocrinas, de la nutrición y del metabolismo que complican el embarazo, el parto y el puerperio.

099.3 Trastornos mentales y enfermedades del sistema nervioso que complican el embarazo, el parto y el puerperio.

O99.4 Enfermedades del sistema circulatorio que complican el embarazo, el parto y el puerperio.

O99.5 Enfermedades del sistema respiratorio que complican el embarazo, el parto y el puerperio.

O99.6 Enfermedades del sistema digestivo que complican el embarazo, el parto y el puerperio.

O99.7 Enfermedades de la piel y del tejido subcutáneo que complican el embarazo, el parto y el puerperio.

O99.8 Otras enfermedades especificadas y afecciones que complican el embarazo, el parto y el puerperio.
Este cambio de escenario epidemiológico obliga a los obstetras a la permanente capacitación en patologías que son del ámbito de la medicina interna, y tenemos el deber ineludible de liderar el equipo multidiciplinario que trate a estas mujeres de alto riesgo materno-perinatal.

Dr. Enrique Donoso S. Editor Jefe.

\section{REFERENCIAS}

1. Instituto Nacional de Estadísticas, Ministerio de Salud. Estadísticas Vitales, 2006.

2. Donoso E. Mortalidad materna en Chile, 2000-2004. Rev Chil Obstet Ginecol 2006;71(4):246-51.

3. Donoso E. Mortalidad materna, Chile 2005 (Editorial). Rev Chil Obstet Ginecol 2008;73(3):143-4.

4. Donoso E, Villarroel L. Edad materna avanzada y riesgo reproductivo. Rev Méd Chile 2003;131(1):55-9.

5. Donoso E, Carvajal J. Maternal, perinatal, and infant outcome of spontaneous pregnancy in the sixth decade of life. Maturitas 2008;59:381-6.

6. Donoso E. Reducción de la mortalidad materna en Chile de 1990 a 2000. Rev Panam Salud Pub 2004;15(5):326-30.

7. Szot J, Moreno C. Mortalidad por aborto en Chile: análisis epidemiológico 1985-2000. Rev Chil Obstet Ginecol 2003;68(4):309-14.

8. Donoso E, Carvajal J, Domínguez MA. Reducción de la fecundidad y envejecimiento de la población de mujeres chilenas en edad fértil: 1990-2004. Rev Méd Chile 2009;137:766-73. 